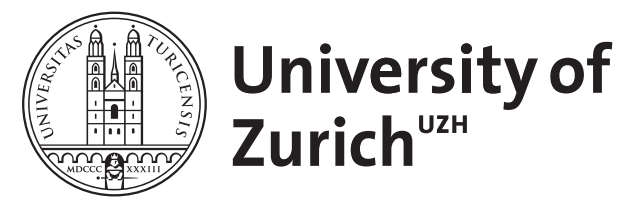

\title{
Market provision of program quality in the television broadcasting industry
}

\author{
Lin, Panlang
}

\begin{abstract}
This paper uses a simple model of duopoly competition to study the market provision of program quality offered by television broadcasters under three different regimes. In regime 1, two broadcasters are financed only with subscription fees (i.e., fee-based or pay TV). In regime 2 , the two broadcasters generate their revenues only from advertising (i.e., free TV). In regime 3, one pay TV broadcaster competes with one free TV broadcaster. We show that the broadcasters in regime 3 (but not in regimes 1 and 2) vertically differentiate their channel programs if, for a given level of advertising market profitability, viewers strongly or weakly dislike the presence of advertising. In such cases, although the two pay TV broadcasters in regime 1 will unambiguously offer higher or lower quality programming than the two free TV broadcasters under regime 2, it is not clear which broadcaster will provide higher or lower program quality in regime 3 because this depends on the degree of horizontal differentiation between the channel programs. However, the levels of quality offered under regimes 1 and 2 fall between the quality levels offered by the two broadcasters in regime 3
\end{abstract}

DOI: https://doi.org/10.2202/1935-1682.2805

Posted at the Zurich Open Repository and Archive, University of Zurich ZORA URL: https://doi.org/10.5167/uzh-154621

Journal Article

Published Version

Originally published at:

Lin, Panlang (2011). Market provision of program quality in the television broadcasting industry. Contributions to Economic Analysis Policy, 11(1):Article 17.

DOI: https://doi.org/10.2202/1935-1682.2805 


\title{
The B.E. Journal of Economic Analysis \& Policy
}

Contributions

\section{Market Provision of Program Quality in the Television Broadcasting Industry}

\author{
Panlang Lin*
}

*University of Zurich, panlang.lin@gmail.com

\section{Recommended Citation}

Panlang Lin (2011) "Market Provision of Program Quality in the Television Broadcasting Industry," The B.E. Journal of Economic Analysis \& Policy: Vol. 11: Iss. 1 (Contributions), Article 17. 


\title{
Market Provision of Program Quality in the Television Broadcasting Industry*
}

\author{
Panlang Lin
}

\begin{abstract}
This paper uses a simple model of duopoly competition to study the market provision of program quality offered by television broadcasters under three different regimes. In regime 1 , two broadcasters are financed only with subscription fees (i.e., fee-based or pay TV). In regime 2, the two broadcasters generate their revenues only from advertising (i.e., free TV). In regime 3, one pay TV broadcaster competes with one free TV broadcaster. We show that the broadcasters in regime 3 (but not in regimes 1 and 2) vertically differentiate their channel programs if, for a given level of advertising market profitability, viewers strongly or weakly dislike the presence of advertising. In such cases, although the two pay TV broadcasters in regime 1 will unambiguously offer higher or lower quality programming than the two free TV broadcasters under regime 2 , it is not clear which broadcaster will provide higher or lower program quality in regime 3 because this depends on the degree of horizontal differentiation between the channel programs. However, the levels of quality offered under regimes 1 and 2 fall between the quality levels offered by the two broadcasters in regime 3.
\end{abstract}

KEYWORDS: television broadcasting, quality provision, advertising, media

*I am very grateful to the editor Helmuth Cremer and to the two anonymous referees for their very useful comments and suggestions that have considerably improved the paper. Any remaining errors are my own. 


\section{Introduction}

Television broadcasters differ in their revenue sources. Pay TV broadcasters generate their revenues from viewer subscription fees, whereas free TV broadcasters are funded by advertising. Pay TV broadcasters operate in a traditional one-sided market in which they sell their products (i.e., television programs) directly to viewers for a given fee. Free TV broadcasters do business in a two-sided market in which they serve two distinct groups of consumers: viewers and advertisers. Free TV broadcasters provide television programs to potential viewers for free and sell adverting space to advertisers. ${ }^{1}$

Indirect network externalities affect the relationship between viewers and advertisers. Viewers typically view advertising as a nuisance because it interrupts the broadcasted programming; the viewer's time budget is not unlimited. Thus, all else being equal, viewers prefer to watch programs on channels that carry less or no advertising. In contrast, advertisers are interested in sending their messages to as many viewers as possible.

The purpose of this paper was to study competition between television broadcasters, with a focus on the market provision of program quality. We propose a simple model of duopoly competition following a Hotelling approach. The broadcasters are horizontally differentiated at an exogenous level, and the quality levels of the channel programs are determined endogenously. We considered three different regimes. Under regime 1, two pay TV broadcasters compete for viewers. Under regime 2, competition exists between two free TV broadcasters. Under regime 3, one pay TV broadcaster competes with one free TV broadcaster. In this way, we investigated how different market structures affect the provision of program quality.

This paper is part of the burgeoning literature on media economics and twosided markets. Theoretical research on the economics of media markets mostly addresses welfare analysis and the choice of media firms regarding program diversity and advertising. Gabszewicz et al. (2002) showed that when a newspaper generates advertising revenue, considerable consequences ensue with regard to the positioning of the newspaper's political opinion. ${ }^{2}$ Under certain circumstances, newspapers have an incentive to minimize the diversity of political opinion. These findings are revolutionary because, according to the solution to the classical location game presented by d'Aspremont et al. (1979), newspapers will always display maximal diversity in political opinion in the absence of advertising revenue. Gal-Or and Dukes (2003) examined a model of location choice in commercial media markets

\footnotetext{
${ }^{1}$ Although viewers are not subjected to a monetary charge, they are indirectly charged because they are forced to watch advertising. However, viewers may be able to skip through advertising breaks by recording programs to watch ex post. We do not consider such situations.

${ }^{2}$ See also Gabszewicz et al. (2001).
} 
and showed that the media have an incentive to minimize the extent of differentiation among themselves; that is, free media firms tend to offer similar content.

Anderson and Coate (2005) presented a theory of the market provision of broadcasting to address the nature of market failure in that industry. They demonstrated that equilibrium advertising levels and the equilibrium amount of programming may be too low or too high, depending on the nuisance cost of advertising for viewers, the substitutability of programs, and the expected benefits to advertisers from reaching viewers through broadcasting. Peitz and Valletti (2008) showed that if viewers strongly dislike advertising, the advertising level under free TV is higher than under pay $\mathrm{TV}^{3}$ They also showed that free TV broadcasters tend to provide less differentiated content, whereas pay TV broadcasters always maximally differentiate their content. Crampes et al. (2009) developed a model of media competition with free entry assuming that media platforms are financed both from advertising receipts and customer subscriptions. ${ }^{4}$ They analyzed how two-sided financing influences quantity and price competition as well as conditions of entry and exit.

The emergence of a theory of two-sided markets over the last decade has had a significant impact on research regarding the economics of media industries. ${ }^{5}$ The interdependence of the two distinct sides of the market (i.e., viewers and advertisers) and the existence of indirect network externalities are characteristic of media industries, which form a typical example of two-sided markets. ${ }^{6}$ As noted by Peitz and Valletti (2008), the two-sided nature of media industries has not been considered in earlier contributions to the literature regarding media economics. ${ }^{7}$ Thus, a theory of two-sided markets allows a more complete picture of media economics to be drawn.

However, little attention has been paid to the study of endogenous quality provisions by media firms in the existing literature. This paper seeks to fill that gap. The model used in this paper is closely related to the model developed by Armstrong (2005), who showed that program quality is higher in a pay TV regime than in a free TV regime. In his paper, pay TV broadcasters placed advertising on their channels, whereas in our paper, this is not the case. We thus consider pure subscrip-

\footnotetext{
${ }^{3}$ Note that in their model, pay TV broadcasters generated revenues from both viewers and advertisers. Moreover, in their study, duopoly competition is captured in two separate regimes, one with two pay TV broadcasters and one with two free TV broadcasters.

${ }^{4}$ They also considered competition between free media platforms.

${ }^{5}$ For examples of the theoretical literature on two-sided markets, see Rochet and Tirole (2003), Wright (2004), Armstrong (2006), Hagiu (2006), Armstrong and Wright (2007), Belleflamme and Toulemonde (2009), Rysman (2009), and Weyl (2010).

${ }^{6}$ For empirical evidence, see, for example, Rysman (2004), Kaiser and Wright (2006), and Kaiser and Song (2009).

${ }^{7}$ Earlier contributions to the literature regarding media economics include Steiner (1952), Beebe (1977), and Spence and Owen (1977).
} 
tion TV without advertising. Moreover, Armstrong (2005) considered two separate regimes in which competition took place either between two pay TV broadcasters or between two free TV broadcasters. However, in reality, pay TV and free TV channels often coexist and compete for viewers in the same market. We thus extend this analysis by introducing asymmetric competition, that is, competition between one pay TV and one free TV broadcaster based on a duopoly model.

The three different regimes represent three different broadcasting industry structures. With this set-up, we can compare program quality under pay TV with that under free TV from two perspectives. First, we can compare program quality provided in a pure pay TV industry with program quality provided in a pure free TV industry (i.e., regime 1 versus regime 2). Second, under regime 3 , we are also able to compare the program quality provided by a pay TV broadcaster with that offered by a free TV broadcaster in the same industry. The former is a cross-industry comparison, whereas the latter is an intra-industry comparison. Moreover, we can also compare all three regimes with one another.

The remainder of this paper is organized as follows: Section 2 introduces the basic model. In Section 3, we conduct equilibrium analysis and present the results. Section 4 concludes the analysis and provides suggestions for future research.

\section{The model}

Suppose that there are two competing channels owned by two different for-profit broadcasters. Let us first consider the case of symmetric competition between two pay TV broadcasters under regime 1. The mass of viewers is normalized to 1 . Suppose that the viewers are uniformly distributed along the unit interval (i.e., the Hotelling segment) and that the two TV channels $i$ and $j$ are located at the two ends of the interval. The location of channel $i$ is $x=0$, whereas that of channel $j$ is $x=1$. The viewers incur a linear transportation cost of $t>0$ per unit of length; that is, a viewer situated at $x$ in the unit interval has a transportation cost of $t x$ when viewing programming on channel $i$ and a transportation cost of $t(1-x)$ when viewing programming on channel $j$. Hence, there is an exogenous level of horizontal program differentiation between the two channels. A lower transport cost of $t$ implies that the programs on the two channels are closer substitutes from the perspective of viewers. Moreover, each viewer chooses only one of the two channels to watch. It is an "either-or" decision. 
The B.E. Journal of Economic Analysis \& Policy, Vol. 11 [2011], Iss. 1 (Contributions), Art. 17

A viewer situated at $x \in[0,1]$ derives the following net utility when watching channel $i$ or $j:^{8}$

$$
u_{v}^{i}=s+q^{i}-p_{v}^{i}-t x, u_{v}^{j}=s+q^{j}-p_{v}^{j}-t(1-x),
$$

where $q^{i}$ and $q^{j}$ are the endogenously determined levels of program quality for the two channels. The subscription fees, which are presented as a lump sum, are characterized by $p_{v}^{i}$ and $p_{v}^{j}$. Throughout the entire analysis, the viewers derive an intrinsic value $s>0$ from watching TV, which is assumed to be sufficiently large so that the viewer market is fully covered. Moreover, we assume that no broadcaster in all three regimes can corner the viewer market; that is, each broadcaster captures a positive market share. Based on the net utility functions in (1), the location $\bar{x}$ of the marginal viewer who is indifferent toward joining channel $i$ or channel $j$ is given by:

$$
\bar{x}=\frac{1}{2}+\frac{q^{i}-q^{j}-p_{v}^{i}+p_{v}^{j}}{2 t} .
$$

Therefore, one can easily derive the following viewer demand functions:

$$
n_{v}^{i}=\bar{x}, n_{v}^{j}=1-\bar{x}
$$

For the sake of simplicity, suppose that the broadcasters incur no marginal cost for serving viewers and that fixed entry costs are not a factor in the analysis. Moreover, assume that the broadcasters face the quadratic fixed costs $\frac{1}{2} c\left(q^{i}\right)^{2}$ and $\frac{1}{2} c\left(q^{j}\right)^{2}$ with $c>0$ as program quality increases. As a result, broadcaster profits are given by:

$$
\begin{aligned}
& \left.\pi^{i}\left(q^{i}, q^{j}, p_{v}^{i}, p_{v}^{j}\right)=\frac{1}{2}+\frac{q^{i}-q^{j}-p_{v}^{i}+p_{v}^{j}}{2 t}\right) p_{v}^{i}-\frac{1}{2} c\left(q^{i}\right)^{2} \\
& \left.\pi^{j}\left(q^{i}, q^{j}, p_{v}^{i}, p_{v}^{j}\right)=\frac{1}{2}+\frac{q^{j}-q^{i}-p_{v}^{j}+p_{v}^{i}}{2 t}\right) p_{v}^{j}-\frac{1}{2} c\left(q^{j}\right)^{2} .
\end{aligned}
$$

Note that all profit functions throughout the entire analysis are assumed to be concave functions in the sense that the second-order conditions for global maxima are satisfied. Moreover, the consumers (that is, the viewers) enjoy the following surplus under regime 1:

$$
\overline{C S}=\int_{0}^{\bar{x}}\left(s+q^{i}-p_{v}^{i}-t z\right) d z+\int_{\bar{x}}^{1}\left(s+q^{j}-p_{v}^{j}-t(1-z)\right) d z .
$$

\footnotetext{
${ }^{8}$ For similar utility and demand motivations with endogenous quality choice in a Hotelling setting, see Sanjo (2007).
} 
We now analyze an industry consisting of two competing free TV channels under regime 2. Maintaining all assumptions and notations designated above, the net utility functions in (1) become:

$$
u_{v}^{i}=s+q^{i}-\gamma n_{a}^{i}-t x, u_{v}^{j}=s+q^{j}-\gamma n_{a}^{j}-t(1-x) .
$$

The viewers are assumed to dislike advertising. Parameter $\gamma>0$ measures the perceived nuisance cost per advertisement. The number of advertisements broadcast on each channel is denoted by $n_{a}^{i}$ and $n_{a}^{j}$. The location $\hat{x}$ of the marginal viewer who is indifferent between the two free TV channels is given by:

$$
\widehat{x}=\frac{1}{2}+\frac{q^{i}-q^{j}-\gamma n_{a}^{i}+\gamma n_{a}^{j}}{2 t} .
$$

The market shares of the broadcasters are as follows:

$$
n_{v}^{i}=\widehat{x}, n_{v}^{j}=1-\widehat{x}
$$

It is reasonable that an advertiser's willingness to pay increases with the number of viewers that the advertiser can reach. We thus assume that each broadcaster's advertising revenue is proportional to the number of viewers it has attracted. If a broadcaster decides to carry $n_{a}$ advertisements on its channel, then it receives advertising revenue of $R\left(n_{a}\right)$ per viewer. ${ }^{9}$ For simplicity's sake, suppose that there are constant returns for broadcast advertising, that is, $R\left(n_{a}\right)=k n_{a}$ and $R^{\prime}\left(n_{a}\right)=k>0$. The parameter $k$ is the broadcaster's unit advertising receipt, which measures the profitability of the advertising market. Following the existing literature, we assume that the broadcasters do not compete for advertisers. ${ }^{10}$ The broadcaster profits are given by:

$$
\begin{aligned}
& \left.\pi^{i}\left(q^{i}, q^{j}, n_{a}^{i}, n_{a}^{j}\right)=\frac{1}{2}+\frac{q^{i}-q^{j}-\gamma n_{a}^{i}+\gamma n_{a}^{j}}{2 t}\right) k n_{a}^{i}-\frac{1}{2} c\left(q^{i}\right)^{2} \\
& \left.\pi^{j}\left(q^{i}, q^{j}, n_{a}^{i}, n_{a}^{j}\right)=\frac{1}{2}+\frac{q^{j}-q^{i}-\gamma n_{a}^{j}+\gamma n_{a}^{i}}{2 t}\right) k n_{a}^{j}-\frac{1}{2} c\left(q^{j}\right)^{2}
\end{aligned}
$$

\footnotetext{
${ }^{9}$ Assume that the free TV broadcasters have reliable technologies to exactly measure the number of viewers watching their channels.

${ }^{10}$ This setting is known as a competitive bottleneck model in the literature regarding two-sided markets; see Armstrong (2006).
} 
The consumer surplus under regime 2 is given by:

$$
\widehat{C S}=\int_{0}^{\widehat{x}}\left(s+q^{i}-\gamma n_{a}^{i}-t z\right) d z+\int_{\widehat{x}}^{1}\left(s+q^{j}-\gamma n_{a}^{j}-t(1-z)\right) d z .
$$

Finally, let us consider the asymmetric competition between one pay TV and one free TV broadcaster under regime 3. Suppose that the pay TV broadcaster is denoted by $i$ and the free TV broadcaster is denoted by $j$. Our notation can be borrowed from the symmetric regimes analyzed above. We thus modify the viewer's net utility functions in (1) or (7) to:

$$
u_{v}^{i}=s+q^{i}-p_{v}^{i}-t x, u_{v}^{j}=s+q^{j}-\gamma n_{a}^{j}-t(1-x) .
$$

The marginal viewer is located at $\tilde{x}$, which is given by:

$$
\widetilde{x}=\frac{1}{2}+\frac{q^{i}-q^{j}-p_{v}^{i}+\gamma n_{a}^{j}}{2 t} .
$$

The broadcasters capture the following market shares:

$$
n_{v}^{i}=\tilde{x}, n_{v}^{j}=1-\tilde{x}
$$

The profits of the broadcasters are given by:

$$
\begin{aligned}
& \left.\pi^{i}\left(q^{i}, q^{j}, p_{v}^{i}, n_{a}^{j}\right)=\frac{1}{2}+\frac{q^{i}-q^{j}-p_{v}^{i}+\gamma n_{a}^{j}}{2 t}\right) p_{v}^{i}-\frac{1}{2} c\left(q^{i}\right)^{2} \\
& \left.\pi^{j}\left(q^{i}, q^{j}, p_{v}^{i}, n_{a}^{j}\right)=\frac{1}{2}+\frac{q^{j}-q^{i}-\gamma n_{a}^{j}+p_{v}^{i}}{2 t}\right) k n_{a}^{j}-\frac{1}{2} c\left(q^{j}\right)^{2} .
\end{aligned}
$$

The consumer surplus under regime 3 is given by:

$$
\widetilde{C S}=\int_{0}^{\widetilde{x}}\left(s+q^{i}-p_{v}^{i}-t z\right) d z+\int_{\widetilde{x}}^{1}\left(s+q^{j}-\gamma n_{a}^{j}-t(1-z)\right) d z
$$

\section{Equilibrium analysis}

For the purpose of explanation, in this section, we conduct an equilibrium analysis by assuming simultaneous games. However, we obtain qualitatively very similar results when we assume sequential games. ${ }^{11}$ Sequential games assume that the

\footnotetext{
${ }^{11}$ Proofs for the sequential games are available from the author upon request.
} 
quality levels of the channel programs are set before the subscription fee (and/or the advertising intensity) is set.

Under regime 1, the pay TV broadcasters simultaneously choose the level of program quality and the subscription fee. Given the profit functions in (4) and (5), the broadcasters solve the following profit maximization problems:

$$
\begin{aligned}
\max _{q^{i}>0, p_{v}^{i}>0} \pi^{i}\left(q^{i}, q^{j}, p_{v}^{i}, p_{v}^{j}\right) & \left.=\frac{1}{2}+\frac{q^{i}-q^{j}-p_{v}^{i}+p_{v}^{j}}{2 t}\right) p_{v}^{i}-\frac{1}{2} c\left(q^{i}\right)^{2} \\
\max _{q^{j}>0, p_{v}^{j}>0} \pi^{j}\left(q^{i}, q^{j}, p_{v}^{i}, p_{v}^{j}\right) & \left.=\frac{1}{2}+\frac{q^{j}-q^{i}-p_{v}^{j}+p_{v}^{i}}{2 t}\right) p_{v}^{j}-\frac{1}{2} c\left(q^{j}\right)^{2} .
\end{aligned}
$$

After solving the corresponding first-order conditions and conducting a few additional computations, we formulate the following lemma:

Lemma 1 Under the unique equilibrium of regime 1, the two competing pay TV broadcasters choose

$$
\bar{q}^{i *}=\bar{q}^{j *}=\frac{1}{2 c} \text { and } \bar{p}_{v}^{i *}=\bar{p}_{v}^{j *}=t
$$

such that

$$
\bar{n}_{v}^{i *}=\bar{n}_{v}^{j *}=\frac{1}{2} \text { and } \bar{\pi}^{i *}=\bar{\pi}^{j *}=\frac{4 c t-1}{8 c} .
$$
isfied: ${ }^{12}$

The following assumption ensures that the second-order conditions are sat-

$$
4 c t>1 \text {. }
$$

Note that assumption (21) also guarantees positive equilibrium profits. Moreover, the following condition ensures that the viewer market is fully covered:

$$
1+2 c s \geq 3 c t
$$

We now discuss properties of the equilibrium solutions given in (19) and (20). It is intuitively clear that when the cost of a quality provision is higher, the level of program quality offered by the broadcasters will be lower under equilibrium conditions. Surprisingly, a higher value of $c$ will increase equilibrium profits. When both broadcasters face higher costs for increasing program quality, then a strategic effect exists that reduces competition, and as a result, equilibrium profits will increase.

\footnotetext{
${ }^{12}$ That is, the partial second own derivatives are negative, and the determinant of the Hessian matrix is positive.
} 
The transportation cost $t$ has a similar strategic effect. A higher value of $t$ indicates that the programs on both channels are less replaceable because they are more horizontally differentiated. A higher level of program differentiation softens price competition such that the broadcasters can charge higher equilibrium subscription fees and achieve higher equilibrium profits. Note that the broadcasters share the viewer market equally.

We now consider the equilibrium analysis for regime 2 . The choice variables for the two competing free TV broadcasters are program quality level and the number of advertisements to be placed. The profit maximization problems are as follows:

$$
\begin{aligned}
\max _{q^{i}>0, n_{a}^{i}>0} \pi^{i}\left(q^{i}, q^{j}, n_{a}^{i}, n_{a}^{j}\right) & \left.=\frac{1}{2}+\frac{q^{i}-q^{j}-\gamma n_{a}^{i}+\gamma n_{a}^{j}}{2 t}\right) k n_{a}^{i}-\frac{1}{2} c\left(q^{i}\right)^{2}, \\
\max _{q^{j}>0, n_{a}^{j}>0} \pi^{j}\left(q^{i}, q^{j}, n_{a}^{i}, n_{a}^{j}\right) & \left.=\frac{1}{2}+\frac{q^{j}-q^{i}-\gamma n_{a}^{j}+\gamma n_{a}^{i}}{2 t}\right) k n_{a}^{j}-\frac{1}{2} c\left(q^{j}\right)^{2} .
\end{aligned}
$$

After solving the corresponding first-order conditions and making a few further computations, we formulate the following lemma:

Lemma 2 Under the unique equilibrium of regime 2, the two competing free TV broadcasters choose

$$
\widehat{q}^{i *}=\widehat{q}^{j *}=\frac{k}{2 c \gamma} \text { and } \widehat{n}_{a}^{i *}=\widehat{n}_{a}^{j *}=\frac{t}{\gamma}
$$

such that

$$
\widehat{n}_{v}^{i *}=\widehat{n}_{v}^{j *}=\frac{1}{2} \text { and } \widehat{\pi}^{i *}=\widehat{\pi}^{j *}=\frac{k(4 c t \gamma-k)}{8 c \gamma^{2}} .
$$

The following assumption is necessary so that the second-order conditions are satisfied: ${ }^{13}$

$$
4 c t \gamma>k
$$

All viewers enter the market if:

$$
k+2 c s \gamma \geq 3 c t \gamma
$$

For the same reasons as those described above regarding the pay TV regime, equilibrium program quality decreases and equilibrium profits increase in $c$. A higher $t$ now allows the broadcasters to increase their amount of advertising (substituting

\footnotetext{
$\overline{{ }^{13} \text { It also guarantees positive equilibrium }}$ profits.
} 
for the subscription fee charged by the pay TV broadcasters in regime 1), leading to higher equilibrium profits. A higher $\gamma$ means that viewers are less willing to watch the program assuming a given number of advertisements and level of program quality. The direct consequence is that the broadcasters will reduce the number of advertisements. The broadcasters will thus have an incentive to lower their program quality level.

We further derive that:

$$
\left.\frac{\partial \hat{\pi}^{i *}}{\partial k}=\frac{\partial \widehat{\pi}^{j *}}{\partial k}>0 \text { and } \frac{\partial \widehat{\pi}^{i *}}{\partial \gamma}=\frac{\partial \widehat{\pi}^{j *}}{\partial \gamma}<0\right) \Leftrightarrow t>\frac{k}{2 c \gamma} .
$$

A higher level of unit advertising receipts $k$ (that is, a more profitable advertising market) will induce broadcasters to provide higher quality programs. Because advertising revenues depend positively on audience size, broadcasters have a vital interest in attracting more viewers by offering higher quality programs. However, this does not necessarily mean that equilibrium profits clearly increase in $k$. On the one hand, a higher $k$ leads to higher quality programs and thus attracts more viewers, thereby generating higher advertising revenues. On the other hand, however, higher levels of $c$ and $\gamma$ will lower the program quality and reduce the number of advertisements and, thus, advertising revenues. Therefore, (27) implies that equilibrium profits increase in $k$ if and only if $t$ is sufficiently large $\left(t>\frac{k}{2 c \gamma}\right)$. The reason is that if the channel programs are sufficiently horizontally differentiated, then the competition for viewers is lessened and more viewers are able to enjoy the programs. As a result, broadcasters can afford to use more advertisements and thus generate higher profits under equilibrium conditions.

We now compare the two symmetric regimes with respect to program quality. By comparing (19) and (23), we observe that two competing free TV broadcasters will offer higher quality programs than two pay TV broadcasters if $\gamma$ is low relative to $k(\gamma<k)$. In this context, a lower level of $\gamma$ leads to more advertising such that free TV broadcasters can make higher advertising revenues for a given level of $k$. As a result, free TV broadcasters have a stronger incentive to offer higher quality programs than do pay TV broadcasters to compensate the viewers for watching more advertising. In contrast, if $\gamma$ is high relative to $k(\gamma>k)$, then advertising revenues are limited due to the reduced advertising intensity and the low level of $k$. As a result, free TV broadcasters will decrease program quality to a lower level than that offered by pay TV broadcasters. However, if neither of these two effects dominates $(\gamma=k)$, then the equilibrium level for program quality will be the same under the pay TV and free TV regimes.

Equivalently, we can state that whether the equilibrium program quality provided in a pure pay TV industry is higher (or lower) than in a pure free TV industry 
crucially depends on how strongly viewers dislike advertising for a given level of advertising market profitability. If the nuisance cost of advertising for viewers is high (or low), then a pure free TV industry will offer a lower (or higher) level of program quality than a pure pay TV industry. However, if the nuisance cost of advertising for viewers is at a medium-level, then a pure pay TV industry will provide the same level of program quality as a pure free TV industry.

We now show that these findings regarding the quality comparison between pay TV and free TV are not complete under asymmetric competition. Under regime 3 , the pay TV broadcaster $i$ chooses a subscription fee, and the free TV broadcaster $j$ chooses an advertising amount in addition to their respective program quality choices. Thus, the two broadcasters solve the following profit maximization problems:

$$
\begin{aligned}
\max _{q^{i}>0, p_{v}^{i}>0} \pi^{i}\left(q^{i}, q^{j}, p_{v}^{i}, n_{a}^{j}\right) & \left.=\frac{1}{2}+\frac{q^{i}-q^{j}-p_{v}^{i}+\gamma n_{a}^{j}}{2 t}\right) p_{v}^{i}-\frac{1}{2} c\left(q^{i}\right)^{2}, \\
\max _{q^{j}>0, n_{a}^{j}>0} \pi^{j}\left(q^{i}, q^{j}, p_{v}^{i}, n_{a}^{j}\right) & \left.=\frac{1}{2}+\frac{q^{j}-q^{i}-\gamma n_{a}^{j}+p_{v}^{i}}{2 t}\right) k n_{a}^{j}-\frac{1}{2} c\left(q^{j}\right)^{2} .
\end{aligned}
$$

After solving the corresponding first-order conditions and conducting a few additional computations, we formulate the following lemma:

Lemma 3 Under the unique equilibrium of regime 3, the two competing pay TV and free TV broadcasters choose

$$
\begin{aligned}
\widetilde{q}^{i *} & =\frac{k-3 c t \gamma}{c(k+\gamma-6 c t \gamma)}, \widetilde{q}^{j *}=\frac{k-3 k c t}{c(k+\gamma-6 c t \gamma)}, \text { and } \\
\widetilde{p}_{v}^{i *} & =\frac{2 t(k-3 c t \gamma)}{k+\gamma-6 c t \gamma}, \widetilde{n}_{a}^{j *}=\frac{2 t(1-3 c t)}{k+\gamma-6 c t \gamma}
\end{aligned}
$$

such that

$$
\begin{aligned}
\widetilde{n}_{v}^{i *} & =\frac{k-3 c t \gamma}{k+\gamma-6 c t \gamma}, \widetilde{n}_{v}^{j *}=\frac{\gamma-3 c t \gamma}{k+\gamma-6 c t \gamma}, \text { and } \\
\tilde{\pi}^{i *} & =\frac{(4 c t-1)(k-3 c t \gamma)^{2}}{2 c(k+\gamma-6 c t \gamma)^{2}}, \tilde{\pi}^{j *}=\frac{k(4 c t \gamma-k)(1-3 c t)^{2}}{2 c(k+\gamma-6 c t \gamma)^{2}} .
\end{aligned}
$$

Note that the second-order conditions are satisfied if assumptions (21) and (25) hold. Moreover, to ensure positive equilibrium solutions in (28)-(31), we must assume in addition to (21) and (25) that: 
Lin: Broadcasting Competition

$$
\begin{aligned}
(k+\gamma-6 c t \gamma)(k-3 c t \gamma) & >0 \\
(k+\gamma-6 c t \gamma)(1-3 c t) & >0
\end{aligned}
$$

Moreover, full coverage of the viewer market requires:

$$
\frac{k(1+c(s-3 t))+c(s-6 c s t+3 t(3 c t-1)) \gamma}{(k+\gamma-6 c t \gamma)} \geq 0 .
$$

For the purpose of explanation, we briefly summarize our main findings regarding quality provisions in the following proposition before continuing to a detailed analysis.

Proposition 1 The broadcasters in regime 3 (but not in regimes 1 and 2) will vertically differentiate their channel programs if, for a given level of advertising market profitability, viewers strongly or weakly dislike the presence of advertising. In such cases, although the two pay TV broadcasters in regime 1 will unambiguously offer higher or lower levels of program quality than the two free TV broadcasters in regime 2, it is not clear which broadcaster will provide higher or lower program quality in regime 3 because this depends on the degree of horizontal differentiation between the channel programs. However, the quality levels offered under regimes 1 and 2 fall between the levels of quality offered by the two broadcasters in regime 3.

For expositional sake, we present Figure 1 below to illustrate the findings given in Proposition 1. We now compare pay TV with free TV in regime 3. From Lemma 3, we derive:

$$
\left(\widetilde{q}^{i *}>\widetilde{q}^{j *}, \widetilde{n}_{v}^{i *}>\widetilde{n}_{v}^{j *}, \tilde{\pi}^{i *}>\widetilde{\pi}^{j *}\right) \text { if }(k-\gamma)[k-(6 c t-1) \gamma]>0 .
$$

There are obviously two critical values of $k$ in (35), namely, $k_{1}=\gamma$ and $k_{2}=$ $(6 c t-1) \gamma$. One can easily check that $k_{1}>k_{2}$ if $3 c t<1$ and $k_{1}<k_{2}$ if $3 c t>1$, where $3 c t=1$ is impossible because of the parameter restriction in (33). As presented in Figure 1, depending on whether $3 c t<1$ or $3 c t>1$, there are two possible situations that satisfy expression (35). The parameter restrictions in (32), (33), and (34) imply that $k \neq(6 c t-1) \gamma$, and thus, a corresponding line does not exist in Figure 1. Moreover, (33) also suggests that if $3 c t<1$, then $k>(6 c t-1) \gamma$, or if $3 c t>1$, then $k<(6 c t-1) \gamma$. It naturally follows that in the same way as under symmetric regimes 1 and 2, the incentives for pay TV and free TV broadcasters to provide program quality under asymmetric competition coincide for $k=\gamma$ (see area $I$ in Figure 1). In equilibrium, the two broadcasters equally share the viewer market and earn the same profits. 
The B.E. Journal of Economic Analysis \& Policy, Vol. 11 [2011], Iss. 1 (Contributions), Art. 17
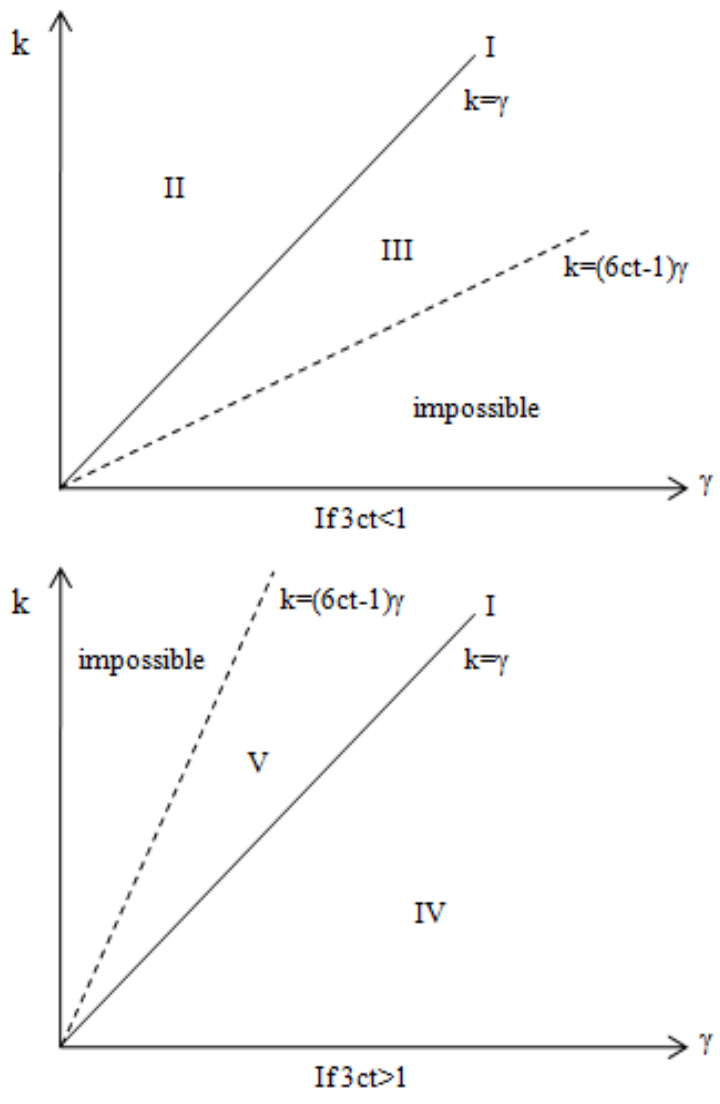

I: All broadcasters offer the same quality in all three regimes.
II, V: Free TV regime 2 offers higher quality than pay TV regime 1.
III, IV: Pay TV regime 1 offers higher quality than free TV regime 2 .
II, IV: Pay TV offers higher quality than free TV in regime 3.
III, V: Free TV offers higher quality than pay TV in regime 3 .
II, III, IV, V: Quality levels in regimes 1 and 2 are ranked between
those in regime 3 .

Figure 1: Market provision of program quality

However, this picture changes if $\gamma$ is low or high relative to $k$. We first analyze the scenario in which the nuisance cost of advertising for viewers is relatively low $(\gamma<k)$ and the channel programs are not sufficiently horizontally differentiated $\left(3 c t<1 \Leftrightarrow t<\frac{1}{3 c}\right)$. This scenario is depicted as area II in Figure 1. In this case, viewers are less likely to pay the subscription fee and join the pay TV channel for the same level of program quality because the channel programs of both pay TV and free TV are similar, and the advertisements do not cause excessive annoyance. This fact naturally leads to the equilibrium outcome that the pay TV broadcaster must offer higher quality programming than its free TV counterpart. Otherwise, there is no justification for the existence of pay TV. However, in pursuing higher-quality 
programming in competition with free TV, the pay TV broadcaster can attract more viewers and make a higher profit.

However, if by $\gamma<k$ the channel programs are sufficiently horizontally differentiated $\left(3 c t>1 \Leftrightarrow t>\frac{1}{3 c}\right)$, then both the pay TV and free TV broadcasters have a certain level of local monopoly power over the provision of quality. The pay TV broadcaster is not required to provide higher quality programming and has less incentive to do so. Given that the nuisance cost of advertising for viewers is relatively low, the free TV broadcaster will dominate the market by offering higher quality programming. The pay TV broadcaster captures a smaller market share by providing a lower level of programming quality on its channel. Moreover, because the nuisance cost of advertising for viewers is relatively low, the free TV broadcaster generally tends to increase advertising intensity, exerting additional upward pressure to provide higher quality programming to compensate viewers. This equilibrium outcome is characterized by area $V$ in Figure 1.

We now analyze equilibrium market outcomes when $k<\gamma$. If the channel programs are sufficiently horizontally differentiated, the pay TV broadcaster will provide higher quality programming, attract more viewers, and make a higher profit than the free TV broadcaster. This is because the nuisance cost of advertising for viewers is relatively high and advertising intensity on the free TV channel thus tends to be low. As a result, the free TV broadcaster has a weak incentive to provide higher quality programming to compensate for advertising and thus attract viewers because advertising revenues are limited. Moreover, because the channel programs are sufficiently horizontally differentiated and viewers strongly dislike advertising, it is difficult for a free TV broadcaster to prevent viewers from joining the pay TV channel. Therefore, in equilibrium, the pay TV broadcaster dominates the market. This outcome is described by area $I V$ in Figure 1.

However, if by $k<\gamma$ the channel programs are not sufficiently horizontally differentiated, the market equilibrium outcome is reversed. The intuition behind this dynamic is straightforward; a lack of sufficiently horizontal program differentiation leads to fierce competition for viewers, and viewers are less willing to pay a subscription fee if they can watch similar programs for free. Despite the high nuisance cost of advertising, the free TV broadcaster can compensate for this by offering higher quality programming and thereby dominating the pay TV broadcaster and attracting more viewers, thus making a higher profit in equilibrium. This market outcome is illustrated in area III in Figure 1.

We now compare all three regimes with respect to the provision of quality. Figure 1 illustrates the results. First, let $\bar{q}^{*} \equiv \bar{q}^{i *} \equiv \bar{q}^{j *}$ and $\widehat{q}^{*} \equiv \widehat{q}^{i *} \equiv \widehat{q}^{j *}$. In area $I$, all broadcasters provide the same program quality under all three regimes $\left(\bar{q}^{*}=\widehat{q}^{*}=\widetilde{q}^{i *}=\widetilde{q}^{j *}\right)$. However, given $k \neq \gamma$, the broadcasters under symmetric competition in regimes 1 and 2 provide higher (or lower) program quality on its 
channels than the broadcaster with lower (or higher) quality channel programming under asymmetric competition in regime 3. To put it more formally, in area $I I$, $\widetilde{q}^{j *}<\bar{q}^{*}<\widehat{q}^{*}<\widetilde{q}^{i *}$, whereas $\widetilde{q}^{i *}<\bar{q}^{*}<\widehat{q}^{*}<\widetilde{q}^{j *}$ holds in area $V$. Moreover, $\widetilde{q}^{i *}<\widehat{q}^{*}<\bar{q}^{*}<\widetilde{q}^{j *}$ occurs in area III, whereas $\widetilde{q}^{j *}<\widehat{q}^{*}<\bar{q}^{*}<\widetilde{q}^{i *}$ exists in area IV.

Stated differently, given $k \neq \gamma$, the quality difference between pay TV and free TV channel programs under asymmetric competition in regime 3 is larger than the quality difference between pay TV and free TV channel programs in regimes 1 and 2. The reasoning behind this is straightforward; given $k \neq \gamma$, asymmetric competition between pay TV and free TV broadcasters in regime 3 leads to the strategic behavior of vertical differentiation. In particular, broadcaster profits will be maximized when the broadcasters offer programs of different quality levels. In contrast, there is no strategic interaction between the pay TV and free TV broadcasters under symmetric competition because regimes 1 and 2 are separate and independent. Consequently, an intra-regime comparison between free TV and pay TV broadcasters implies a larger quality difference between pay TV and free TV. After all, regime 3 features a direct strategic interaction between pay TV and free TV broadcasters rather than the cross-regime comparison between the pay TV and free TV broadcasters under regimes 1 and 2.

As an additional step, we now compare the subscription fee and advertising intensity under symmetric competition in regimes 1 and 2 with that under asymmetric competition in regime 3 . First, let $\bar{p}_{v}^{*} \equiv \bar{p}_{v}^{i *} \equiv \bar{p}_{v}^{j *}$ and $\widehat{n}_{a}^{*} \equiv \widehat{n}_{a}^{i *} \equiv \widehat{n}_{a}^{j *}$. We derive:

$$
\left(\bar{p}_{v}^{*}<\widetilde{p}_{v}^{i *} \text { and } \widehat{n}_{a}^{*}>\widetilde{n}_{a}^{j *}\right) \text { if }(k-\gamma)[k-(6 c t-1) \gamma]>0 .
$$

In the knife-edge case $k=\gamma$, the equilibrium subscription fee and advertising intensity are the same in all three regimes. Moreover, by comparing (36) with (35), we note that the broadcaster with higher quality programming in regime 3 is able to charge a higher subscription fee or set a higher advertising level than the broadcasters under symmetric competition in regimes 1 and 2 . In contrast, the broadcaster with lower quality programming in regime 3 offers a lower subscription fee or sets a lower advertising level than do the broadcasters under symmetric competition in regimes 1 and 2. The reason is simple and arises from Proposition 1; given $k \neq \gamma$, the quality levels of channel programs in regimes 1 and 2 are ranked between the quality levels offered by the two broadcasters in regime 3 .

Finally, we examine the effects of the three different market structures on consumer (i.e., viewer) surplus. In which regime and under what circumstances do viewers enjoy the greatest surplus? First, we compute the equilibrium consumer surplus in each regime. Inserting the relevant equilibrium solutions from Lemma 1 
into (6), we calculate that the consumer surplus in regime 1 is given by:

$$
\overline{C S}^{*}=\frac{2+4 c s-5 c t}{4 c}>0 .
$$

Equivalently, the consumer surplus in regime 2 is given by:

$$
\widehat{C S}^{*}=\frac{2 k+4 c s \gamma-5 c t \gamma}{4 c \gamma}>0 \text {. }
$$

In regime 3 , the consumer surplus is given by:

$$
\widetilde{C S}^{*}=\frac{k^{2} \Phi-2 k \gamma \Omega+c \gamma^{2} \Psi}{2 c(k+\gamma-6 c t \gamma)^{2}}>0,
$$

with

$$
\begin{aligned}
\Phi & =(2+2 c s-5 c t) \\
\Omega & =[-1-2 c(s-6 c s t+6 t(2 c t-1))] \\
\Psi & =\left[2 s(1-6 c t)^{2}+t(6 c t(8-15 c t)-5)\right] .
\end{aligned}
$$

From previous analysis, it naturally follows that based on $k=\gamma$, the consumer surplus in all three regimes is actually the same. We now consider the case when $k<\gamma$. Here, viewers are clearly better off under regimes 1 and 3 than regime $2 .{ }^{14}$ Because the nuisance cost of advertising for viewers is relatively high, the additional benefit of avoiding advertising is so large that viewers clearly prefer regimes 1 and 3, as these regimes provide the pay TV option. Moreover, for the case $k<\gamma$, it is ambiguous whether the viewers are better off under regime 1 than regime 3:

$$
\overline{C S}^{*}>\widetilde{C S}^{*} \Leftrightarrow 2\left(k+\gamma+18 c^{2} t^{2} \gamma\right)>c t(5 k+19 \gamma) .
$$

Two opposing effects are responsible for this finding. Compared to the symmetric, pure pay TV regime 1, the channel programs under asymmetric competition in regime 3 are vertically differentiated, increasing viewer welfare. However, vertical differentiation of channel programs also means that a broadcaster can charge more from viewers by setting higher subscription fees or enhancing advertising intensity because broadcaster competition is lessened somewhat.

\footnotetext{
${ }^{14}$ Formally: $\left(\overline{C S}^{*}, \widetilde{C S}^{*}\right)>\widehat{C S}^{*}$ if $k<\gamma$.
} 
What happens when $k>\gamma$ ? In this case, the viewers enjoy higher surpluses under regimes 2 and 3 than under the pure pay TV regime, regime $1 .{ }^{15}$ When the nuisance cost of advertising for viewers is relatively low, viewers are less willing to pay the subscription fee necessary to watch a pay TV channel. This effect predominates such that regime 1, in which there is no free TV available, generates the lowest surplus. By comparing regimes 2 and 3, we obtain the following for the case $k>\gamma$ :

$$
\widehat{C S}^{*}>\widetilde{C S}^{*} \Leftrightarrow 2\left(k^{2}+k \gamma+18 c^{2} t^{2} \gamma^{2}\right)>c t\left(5 \gamma^{2}+19 k \gamma\right) .
$$

The explanation applied to (40) can be applied to (41); compared to the symmetric, pure free TV regime 2, vertical differentiation of the channel programs in regime 3 has both welfare-enhancing and welfare-reducing effects on viewers at the same time such that direct comparison between the two regimes leads to an ambiguous result.

\section{Conclusion}

This paper has presented a stylized model of duopoly competition between TV broadcasters. The main purpose was to analyze the provision of program quality by broadcasters in three different market structures. Under regime 1, two pay TV broadcasters compete for viewers. Under regime 2, there is competition between two free TV broadcasters. Under regime 3, one pay TV broadcaster competes with one free TV broadcaster. We show that the incentives to offer programming quality depend mainly on the nuisance cost of adverting for viewers, the broadcaster's marginal return on advertising, and the degree of horizontal differentiation between the competing channel programs.

Intervention or regulation in the TV broadcasting industry usually emphasizes the degree of horizontal differentiation and the quality of channel programming. Policy makers develop initiatives so that diverse and high-quality programming is widely provided to consumers by the market. ${ }^{16}$ Whereas the diversity of channel programming (and advertising intensity) has been investigated in the existing literature, our conceptual framework can serve as a guide for policy makers interested in to the market behavior of quality provisions. We want to emphasize two aspects of our analysis.

First, one might assume that program quality under pay TV is higher than under free TV because viewers are willing to pay a fee for higher quality programming. Armstrong (2005) demonstrated that this is true if pay TV broadcasters also carry advertising on the channels. However, we have shown that this claim does not

${ }^{15}$ Formally: $\left(\widehat{C S}^{*}, \widetilde{C S}^{*}\right)>\overline{C S}^{*}$ if $k>\gamma$.

${ }^{16}$ See also Armstrong (2005). 
hold under certain circumstances if the pay TV broadcasters do not allow advertising (that is, pure subscription TV). Second, under certain circumstances, content regulation with respect to program diversity will also affect the market provision of program quality in regime 3, but not in regimes 1 and 2. For example, if a policy maker increases program diversity too much, the quality levels provided by pay TV and free TV broadcasters will be reversed. This could lead to undesirable welfare effects from the perspective of the policy maker. Thus, it is essential for policy makers to consider such cross externalities in content regulation.

We have assumed that viewers watch only one channel, which in some scenarios is an appropriate assumption. For example, it is reasonable that a viewer will choose to watch only one of two movies that are showing at the same time on different channels. However, viewers often watch several channels sequentially. For example, a viewer may choose to watch two movies showing sequentially on different channels if both movies appeal to the viewer. Thus, capturing this type of viewer behavior would make the model more realistic. Another fruitful direction for future research would be to incorporate the assumption that viewers have heterogeneous preferences regarding program quality.

In this study, we also assumed that advertisers are homogeneous. A natural extension would be the introduction of heterogeneous advertisers with a differential willingness to pay. One might follow the approaches developed in Armstrong (2006) and Peitz and Valletti (2008). However, this would lead to serious computational problems for both simultaneous and sequential games in our setting. For this reason, this is left for future research. Moreover, we also assumed that the advertisers place advertising on both channels if they want to reach all viewers (i.e., multi-homing advertisers), thus ruling out the possibility of broadcaster competition on the advertiser side (i.e., single-homing advertisers). Broadcasters have local monopoly power on the advertiser side. However, it might be interesting to extend this analysis by introducing broadcaster competition in attracting advertisers. A more complicated case would be to model the partial multi-homing behavior of advertisers, which involves both multi-homing advertisers and single-homing advertisers.

A far more ambitious approach for future research than that presented here would analyze a larger game with more endogenous decisions made by broadcasters. For example, in stage 1, broadcasters might choose their business model, that is, either pay TV (with or without advertising) or free TV. In stage 2, the broadcasters would then choose the level of diversity across their channel programs. In stage 3 , the broadcasters would decide on which level of program quality to offer, and in stage 4 , the broadcasters would make final decisions to set market pricing and/or advertising intensity. 
Finally, we have analyzed competition between private for-profit broadcasters. However, public service broadcasters also operate in the markets. One possible extension could be to introduce asymmetric competition between private for-profit and public service broadcasters. Depending on the country, public service broadcasters (such as the BBC in the UK) may be funded by television license fees, government grants, and public donations. Country-specific differences also exist regarding advertising and content regulations, for example, regarding whether or not advertising is allowed, on what level is it allowed, and whether content is regulated. It is also important to specify the objectives of public service broadcasters first, as the objective of private broadcasters is clear.

\section{References}

Anderson, S. and Coate, S. (2005), 'Market Provision of Broadcasting: A Welfare Analysis', Review of Economic Studies 72, 947-972.

Armstrong, M. (2005), 'Public Service Broadcasting', Fiscal Studies 26(3), 281299.

Armstrong, M. (2006), 'Competition in Two-Sided Markets', RAND Journal of Economics 37(3), 668-691.

Armstrong, M. and Wright, J. (2007), 'Two-Sided Markets, Competitive Bottlenecks and Exclusive Contracts', Economic Theory 32(2), 353-380.

Beebe, J. (1977), 'Institutional Structure and Program Choices in Television Markets', Quarterly Journal of Economics 91(1), 15-37.

Belleflamme, P. and Toulemonde, E. (2009), 'Negative Intra-Side Externalities in Two-Sided Markets', International Economic Review 50(1), 245-272.

Crampes, C., Haritchabalet, C. and Jullien, B. (2009), 'Advertising, Competition and Entry in Media Industries', Journal of Industrial Economics 57(1), 7-31.

d'Aspremont, C., Gabszewicz, J. and Thisse, J. (1979), 'On Hotelling's" Stability in Competition"', Econometrica 47(5), 1145-1150.

Gabszewicz, J., Laussel, D. and Sonnac, N. (2001), 'Press Advertising and the Ascent of the "Pensee Unique"', European Economic Review 45(4-6), 641651. 
Gabszewicz, J., Laussel, D. and Sonnac, N. (2002), 'Press Advertising and the Political Differentiation of Newspapers', Journal of Public Economic Theory 4(3), 317-334.

Gal-Or, E. and Dukes, A. (2003), 'Minimum Differentiation in Commercial Media Markets', Journal of Economics \& Management Strategy 12(3), 291-325.

Hagiu, A. (2006), 'Pricing and Commitment by Two-Sided Platforms', Rand Journal of Economics 37(3), 720-737.

Kaiser, U. and Song, M. (2009), 'Do Media Consumers Really Dislike Advertising? An Empirical Assessment of the Role of Advertising in Print Media Markets', International Journal of Industrial Organization 27(2), 292-301.

Kaiser, U. and Wright, J. (2006), 'Price Structure in Two-Sided Markets: Evidence from the Magazine Industry', International Journal of Industrial Organization 24(1), 1-28.

Peitz, M. and Valletti, T. (2008), 'Content and Advertising in the Media: Pay-tv versus Free-to-air', International Journal of Industrial Organization 26(4), 949965.

Rochet, J. and Tirole, J. (2003), 'Platform Competition in Two-Sided Markets', Journal of the European Economic Association 1(4), 990-1029.

Rysman, M. (2004), 'Competition between Networks: A Study of the Market for Yellow Pages', Review of Economic Studies 71(2), 483-512.

Rysman, M. (2009), 'The Economics of Two-Sided Markets', Journal of Economic Perspectives 23(3), 125-143.

Sanjo, Y. (2007), 'Hotelling's Location Model with Quality Choice in Mixed Duopoly', Economics Bulletin 18(2), 1-11.

Spence, M. and Owen, B. (1977), 'Television Programming, Monopolistic Competition, and Welfare', Quarterly Journal of Economics 91(1), 103-126.

Steiner, P. (1952), 'Program Patterns and Preferences, and the Workability of Competition in Radio Broadcasting', Quarterly Journal of Economics 66(2), 194223. 
The B.E. Journal of Economic Analysis \& Policy, Vol. 11 [2011], Iss. 1 (Contributions), Art. 17

Weyl, E. G. (2010), 'A Price Theory of Multi-Sided Platforms', American Economic Review 100(4), 1642-1672.

Wright, J. (2004), 'One-Sided Logic in Two-Sided Markets', Review of Network Economics 3(1), 44-64. 